FUNÇÃo ECONÔMICA E INTERPRETAÇÃO DA ESCRITURA DE EMISSÃO DE DEBÊNTURES NO DIREITO BRASILEIRO

\author{
DissertaÇÃo DE Mestrado
}

OrIENTADORA: Professora Titular Dra. Paula Andrea Forgioni

UNIVERSIDADE DE SÃO PAULO

FACULDADE DE DIREITO

São Paulo/SP 
FUNÇÃo ECONÔMICA E INTERPRETAÇÃO DA ESCRITURA DE EMISSÃO DE DEBÊNTURES NO DIREITO BRASILEIRO

Dissertação apresentada a Banca Examinadora do Programa de Pós-Graduação em Direito, da Faculdade de Direito da Universidade de São Paulo, como exigência parcial para obtenção do título de Mestre em Direito, na área de concentração de Direito Comercial, sob a orientação da Professora Titular Dra. Paula Andrea Forgioni.

UNIVERSIDADE DE SÃO PAULO

FACULDADE DE DIREITO

\section{São Paulo/SP}




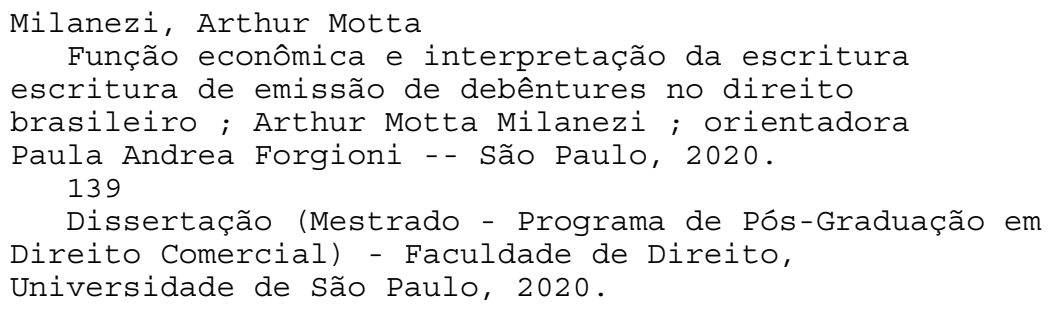

1. Debêntures. 2. Escritura de emissão de debêntures. 3. Oferta pública. 4. Oferta privada. 5. Interpretação. I. Forgioni, Paula Andrea, orient. II. Título. 
Nome: MILANEZI, Arthur Motta.

Título: Função econômica e interpretação da escritura de emissão de debêntures no direito brasileiro

Dissertação apresentada a Banca Examinadora do Programa de Pós-Graduação em Direito, da Faculdade de Direito da Universidade de São Paulo, como exigência parcial para obtenção do título de Mestre em Direito.

Aprovada em:

Banca Examinadora

Prof. Dr. Instituição:

Julgamento: Assinatura:

Prof. Dr. Instituição:

Julgamento: Assinatura:

Prof. Dr. Instituição: Assinatura: 


\section{AGRADECIMENTOS}

Muitas intempéries passa o estudante de Direito que se dispõe a realizar o curso de pós-graduação stricto sensu da Faculdade de Direito da Universidade de São Paulo. Comigo não foi diferente. Após quatro anos de estudo, entre elaboração de projeto e defesa desta dissertação, quase tudo mudou: minha visão de vida, minha perspectiva acadêmica e profissional, meu intelecto, minhas relações. A despeito disso, empreguei, nesses quatro anos, todo o meu esforço e suor para que o resultado desta dissertação servisse como uma contraprestação verdadeiramente útil à comunidade. Esse sempre foi o meu guia para enfrentar as naturais barreiras que se apresentam a um jovem estudante durante sua pesquisa.

Entretanto, limitar a dizer que este trabalho é apenas fruto do meu empenho seria egoísmo. Muitas pessoas fazem parte desta etapa. Ainda que não pelo auxílio direto à realização do trabalho, transmitiram-me paz e serenidade em conversas ou mensagens que garantiram a mim forças para que eu prosseguisse com minha função acadêmica. Mesmo que não me refira nomeadamente, saberão que fazem parte disso ao lerem este singelo agradecimento.

À Prof. ${ }^{a}$ Paula A. Forgioni que, sem saber a fundo minha aptidão, confiou-me a missão. Ser seu orientando elevou meu nível intelectual e me trouxe grande experiência acadêmica. Serei eternamente grato e tentarei, ao máximo, continuar a propagar a boa doutrina comercial, como ela faz brilhante e incansavelmente.

Aos meus pais e irmão que sempre me ensinaram a importância de nunca se desviar de seus valores e de sempre lutar para entregar o melhor naquilo que se responsabilizou. Lições valiosas que foram imprescindíveis para o resultado desta dissertação. Foram vocês que, quando mais precisei, estiveram ao meu lado para mostrar as coisas boas que a vida me guarda.

Aos meus companheiros de trabalho enquanto estive em São Paulo. Ao Marques Rosado, Toledo César e Carmona Advogados, pela valiosa experiência de ter trabalhado ao lado de profissionais tão capacitados e, sobretudo, dedicados. Agradeço à Maria do Céu, Prof. ${ }^{\circ}$ Carlos Alberto Carmona, Denis Giamondo Gierse, José Fernando de Mendonça Gomes Neto, José Augusto Bitencourt Machado e a toda a equipe do contencioso. Levarei a experiência de ter trabalhado com vocês por toda a vida. Não posso deixar de agradecer à Alessandra Martins de Souza, Natasha Midori Hinata e Mauro Vitória do Nascimento Neto 
Marchiori, companheiros de Azevedo Sette Advogados, que tão bem me acolheram logo quando me mudei para São Paulo.

Aos meus irmãos da vida, meus amigos de Campinas e de Ribeirão Preto. Obrigado pelo companheirismo e por sempre me lembrarem que são as coisas simples da vida que devem ser valorizadas. Peço que nossa amizade continue assim, apesar da distância. Vê-los felizes e participar da vida de cada um me faz uma pessoa melhor.

Por fim, à Jéssica Pedro e sua querida família: "Para ser grande, sê inteiro: nada teu exagera ou exclui. Sê todo em cada coisa. Põe quanto és no mínimo que fazes. Assim em cada lago a lua toda brilha, porque alta vive". Vocês fazem parte também. Obrigado por cada momento. 


\section{RESUMO}

MILANEZI, Arthur Motta. Função econômica e interpretação da escritura de emissão de debêntures no direito brasileiro. 2020. 139 f. Dissertação (Mestrado em Direito Comercial) - Faculdade de Direito, Universidade de São Paulo, São Paulo, 2020.

Desde a Lei n. ${ }^{\circ}$ 3.150/1882 até a Lei das S.A., a debênture foi historicamente regida pelo nosso ordenamento jurídico para cumprir a função de um título de dívida capaz de, mediante oferta pública ao mercado, operacionalizar a obtenção de recursos financeiros perante uma coletividade de indivíduos. Por outro lado, é importante reconhecer, igualmente, que a Lei não desautoriza a oferta privada de debêntures. Entre um contexto e outro, é possível notar que o privado detém um terreno mais fértil ao exercício da autonomia privada dos agentes por não se tratar de um negócio massificado, mas sim de cunho íntimo e peculiar. Assim, deixa a debênture de se mostrar, na prática, invariavelmente como um título de dívida destinado a angariar capital financeiro de modo pulverizado e despersonalizado. As condições da escritura de emissão, por sua vez, não devem ser sempre encaradas como unilateralmente concebidas pela companhia emissora, conforme normalmente ocorre nas colocações públicas de debêntures. Nas operações privadas, a tendência é que os debenturistas negociem as cláusulas antes de os títulos serem emitidos, não simplesmente aderindo ao que foi apresentado pela companhia. A partir dessa visão - mais adstrita à realidade do mercado -, observam-se relevantes lições sobre interpretação de escritura de emissão de debêntures. Considerando que as escrituras destinadas à colocação pública contêm cláusulas determinadas pelo mercado, e não em função do dinamismo do processo negocial, como se dá nas de caráter privado, imperioso destacar que o conteúdo daquelas deve ser interpretado de maneira mais restrita em comparação a estas para que haja guarida aos usos e costumes. Ademais, a correta aplicação dos arts. 112, 133, 422, 423 e 157, todos do Código Civil, passa necessariamente pela devida compreensão dos mencionados contextos em que escrituras de emissão podem ser levadas a efeito.

Palavras-chave: debêntures - escritura de emissão - ofertas públicas - ofertas privadas interpretação. 


\begin{abstract}
MILANEZI, Arthur Motta. Economic function and interpretation of trust indenture in Brazilian law. 2020. 139 p. Dissertation (Master's degree) - Faculty of Law, University of São Paulo, São Paulo, 2020.

From Law n. ${ }^{\circ} 3.150 / 1882$ to Brazilian Corporate Law, the debenture has historically been governed by our legal system to fulfill the function of a debt security capable of operationalize the obtaining of financial resources with a collectivity of individuals. On the other hand, it is also important to recognize that the law does not disallow the private offering of debentures. Between one context and another, it is possible to notice that the private one holds more fertile ground to the exercise of the private autonomy of the economic agents because it is not a mass business, but one of an intimate and peculiar nature. Thus, it ceases the debenture to be invariably presented in practice as a debt security designed to raise financial capital in a pulverized and depersonalized manner. The conditions of the trust indenture, in turn, should not be viewed as unilaterally conceived by the issuing company, as normally occurs in public placement of debentures. In private operations, debenture holders tend to negotiate clauses before the securities are issued, not simply adhering to what was exclusively presented by the company. From this view - more closely related to the reality of the market - we can see valuable lessons on interpreting trust indentures. Considering that the trust indentures intended for public placement have clauses determined by the market and not due to the dynamism of the negotiation process, as in the case of private ones, it is imperative to emphasize that the content of these must be interpreted more narrowly in order to protect the market's consuetude. In addition, the correct application of articles 112, 133, 422, 423 and 157, all of the Brazilian Civil Code, necessarily requires proper understanding of the aforementioned contexts in which trust indentures may be carried out.
\end{abstract}

Keywords: debentures - trust indenture - public offerings - private placements - interpretation. 


\section{SUMÁRIO}

CAPÍTULO 1 - INTRODUÇÃO .............................................................................11

1.1 Considerações iniciais e delimitação do objeto de pesquisa .................................11

1.2 Estruturação do trabalho considerando o objeto de pesquisa proposto ...................14

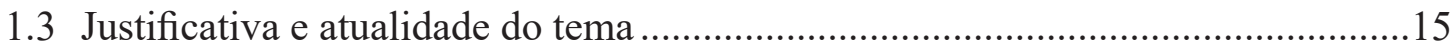

\section{CAPÍTULO 2 - ANÁLISE DAS FORMAS DE COLOCAÇÃO DE DEBÊNTURES NO}

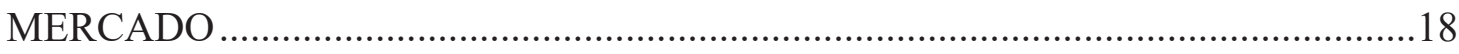

2.1 Ponderações iniciais: o estudo das formas de colocação de debêntures como

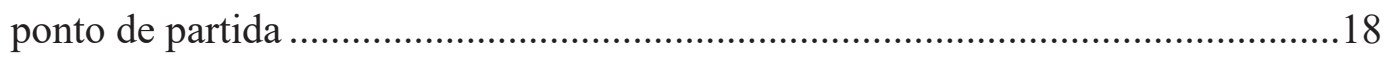

2.2 Breves considerações a respeito da evolução normativa da debênture no Direito brasileiro

2.2.1 Da primeira disciplina legal ao Decreto 177-A, de 15 de setembro de 1893

2.2.2 A promulgação da Lei das S.A. e a modernização do regime jurídico da debênture

2.2.3 O regime jurídico da debênture historicamente concebido para regê-la enquanto veículo de captação pulverizada de recursos 30

2.3 As formas de colocação de debêntures e seus efeitos à compreensão da debênture e da escritura de emissão

2.3.1 Os estágios da emissão de debêntures segundo a doutrina nacional: criação, emissão e colocação

2.3.2 Colocações públicas e privadas de debêntures e seus diferentes contextos de consumação

2.3.3 Considerações finais: definição de premissas a partir das formas de colocação

3.1 A debênture possui uma única função ou pode exercer diversas finalidades econômicas?

3.2 A natureza jurídica da debênture: uma investigação histórico-doutrinária 
3.2.1 Teoria contratualista e a debênture como uma fração de um contrato de mútuo sui generis

3.2.2 Teoria geral dos títulos de crédito e a inclusão da debênture nesse gênero... 56

3.2.3 Surgimento do mercado de capitais e a debênture como valor mobiliário.... 60

3.2.4 Inexistência de uma classificação constante e válida para todas as debêntures

3.3 Considerações conclusivas sobre a caracterização da debênture .66

\section{CAPÍTULO 4 - A CARACTERIZAÇÃO DA ESCRITURA DE EMISSÃO DE}

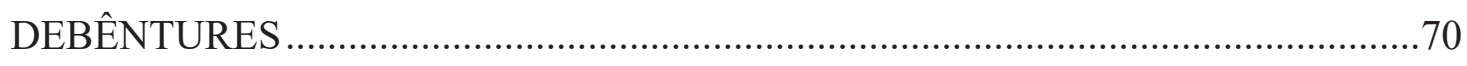

4.1 A função econômica da escritura de emissão de debêntures

4.2 A natureza jurídica da escritura de emissão de debêntures segundo a doutrina nacional.

4.3 Ainda sobre a natureza jurídica: a relação estabelecida entre companhia e debenturistas após a formalização da escritura de emissão

4.4 Um estudo empírico a respeito da concepção da relação entre companhia e debenturistas em emissões públicas e privadas

4.4.1 Escrituras de emissão de debêntures celebradas com a finalidade de angariar recursos financeiros no mercado de capitais

4.4.2 Escrituras de emissão de debêntures celebradas com a finalidade de angariar recursos de um único fundo de investimento em participações ... 87

4.5 Considerações conclusivas: a escritura de emissão e a forma de colocação das debêntures

\section{CAPÍTULO 5 - ELEMENTOS PARA INTERPRETAÇÃO DE ESCRITURA DE EMISSÃO DE DEBÊNTURES NO DIREITO BRASILEIRO}

5.1 A limitação ao pleno exercício da autonomia privada imposto pela Lei das S.A.... 96

5.2 As diretrizes gerais de interpretação de escritura de emissão de debêntures ......100

5.3 Diretrizes específicas: a aplicação das regras de intepretação do Código Civil à escritura de emissão de debêntures.

5.3.1 Art. 112: da finalidade econômica à intenção comum das partes.

5.3.2 Arts. 113 e 422: a boa-fé objetiva e os usos e costumes.

5.3.3 Art. 423: a interpretação a favor do aderente/devedor

5.3.4 Art. 157: proteção à parte mais fraca a partir da identificação da lesão ... 120 


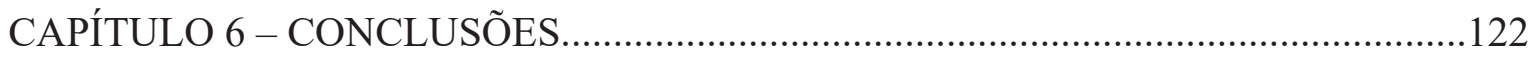

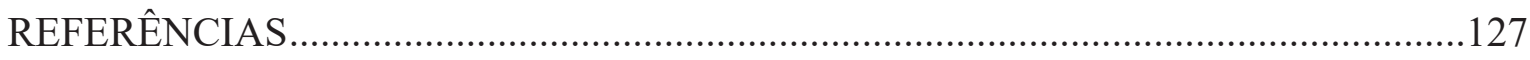

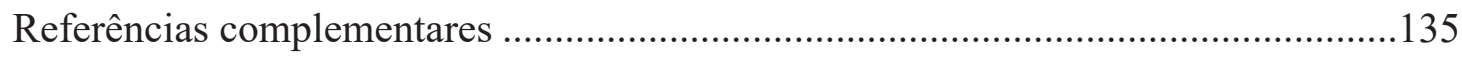




\section{CAPÍTULO 1 \\ INTRODUÇÃO}

\subsection{Considerações iniciais e delimitação do objeto de pesquisa}

A inquietação inicial que provocou a estruturação e elaboração desta dissertação foi, de um lado, o recente crescimento da importância das debêntures ao financiamento de companhias brasileiras e, de outro, a escassez de trabalhos monográficos abordando esse tema no Brasil. Segundo YAZBEK ${ }^{1}$, os estudos sobre a debênture encontram-se muito próximos aos debates sobre o mercado de capitais e os instrumentos nele negociados. Considerando que, historicamente, a debênture não foi um título relevante ao funding das companhias, não havia demanda por maiores formulações teóricas a respeito.

Entretanto, essa situação está progressivamente mudando. De acordo com a análise do Instituto de Estudos para o Desenvolvimento Industrial (IEDI) ${ }^{2}$, se o cenário atual se mantiver, com taxa real de juros em níveis mais próximos das internacionais e a redução da atuação do Banco Nacional de Desenvolvimento Econômico e Social (BNDES), que passou a adotar taxas de financiamento referenciadas a taxas de mercado (TLP), "existem razões para acreditar que o mercado de capitais tem potencial de crescimento suficiente para se transformar na principal fonte de recursos de financiamento de longo prazo na economia brasileira". Com efeito, nota-se que o volume de emissões de debêntures no mercado de capitais em 2018 e em 2019, até o mês de outubro, é substancialmente maior do que foi emitido nos anos de 2013, 2014, 2015 e $2016^{3}$.

1 YAZBEK, Otávio. A modernização do regime das debêntures e a criação de um mercado de dívida de longo prazo no Brasil. In: CASTRO, Rodrigo R. Monteiro et al. (coord.). Direito empresarial e outros estudos de direito em homenagem ao Professor José Alexandre Tavares Guerreiro. São Paulo: Quartier Latin, 2013. p. 565-566.

2 ROCCA, Carlos. Financiamento do investimento no Brasil e o papel do mercado de capitais. In: ALMEIDA, Julio Sergio Gomes de; CAGNIN, Rafael Fagundes (org.). BNDES, mercado de capitais e o financiamento de longo prazo no Brasil. São Paulo: Instituto de Estudos para o Desenvolvimento Industrial - IEDI, 2018. Disponível em: https://www.iedi.org.br/media/site/artigos/20181128_bndes.pdf. Acesso em: 7 jul. 2019.

3 Conforme informa o boletim de mercado de capitais publicado mensalmente pela Associação Brasileira das Entidades dos Mercados Financeiro e de Capitais (ANBIMA), em 2018 o volume de emissão de debêntures foi de R \$ 153,716 bilhões. Até outubro de 2019, o volume foi de R\$ 138,493 bilhões. Entre 2013 a 2016, o maior volume de emissões ocorreu em 2014, momento em que R \$ 75,362 bilhões foram captados via emissão de debêntures. Disponível em: https://www.anbima.com.br/pt_br/informar/relatorios/mercadode-capitais/boletim-de-mercado-de-capitais/mercado-de-capitais-registra-captacao-de-r-312-bilhoes-noano.htm. Acesso em: 23 abr. 2019. 
Diante do potencial que a debênture pode apresentar no atual cenário econômico como instrumento de captação de recursos, cabe aos pesquisadores do Direito revisitar a matéria para criarem um corpus doutrinário mais consistente a respeito de seus diversos aspectos. Em linhas gerais, os estudos sobre a debênture no Brasil situam-se em tratados de Direito Comercial ou em obras que analisam e comentam cada artigo da Lei das S.A. ou da Lei n. ${ }^{\circ}$ 6.385/1976. Existe pouca - ou mesmo nenhuma, em alguns casos - produção científica elaborada exclusivamente sobre a debênture ou temas relacionados.

A escritura de emissão, por exemplo, é um desses temas que, não obstante sua relevância, ainda não foi enfrentado direta e especificamente pela doutrina. $O$ art. 61 da Lei das S.A. estabelece que a companhia que emitir debêntures deverá fazer constar desse documento os direitos conferidos pelos títulos emitidos, suas garantias e demais cláusulas e condições. Nesse sentido, a celebração pela companhia de uma escritura que determine as "regras do jogo" é indispensável para que debêntures sejam emitidas no mercado.

Ao estudar a doutrina, clássica e atual, constata-se que os autores apresentam a debênture como título representativo de dívida que se presta, na sua essência, a captar recursos à companhia de maneira pulverizada e despersonalizada no mercado. Sob esse olhar instrumental a respeito da debênture, esse corpo doutrinário entende a escritura de emissão como um documento elaborado unilateralmente pela companhia emissora. Da escritura, portanto, emergiriam termos e condições não barganhados, cabendo aos debenturistas interessados na aquisição dos títulos emitidos a mera adesão ao conteúdo proposto pela companhia.

Se a análise recair tão somente sobre as colocações de debêntures levadas a efeito no mercado de capitais, esse entendimento se encontraria muito próximo da realidade, pois, por via de regra, a oferta de debêntures nesses casos se perfaz indistintamente aos investidores. Devido aos custos de transação, uma emissão como essa seria economicamente inviável, caso a companhia tivesse que negociar o conteúdo da escritura de emissão com cada interessado. Por essa razão, a companhia elabora unilateralmente os termos e as condições da escritura, observada a conjuntura do mercado, e apresenta aos investidores na forma de uma oferta. Aquele que a entender como um bom negócio, segundo sua ponderação entre risco e retorno, aderirá aos termos propostos mediante a subscrição dos títulos. Logo, o conteúdo da escritura de emissão não seria, nesses casos, resultado de uma barganha entre os agentes.

No entanto, não só no mercado de capitais que debêntures são emitidas. Paralelamente, esses títulos são ofertados e subscritos de maneira privada entre partes 
determinadas. Agentes financeiros específicos (como acionistas da companhia, bancos ou fundos de investimentos), na prática, negociam e adquirem a totalidade de debêntures emitidas por uma empresa sob uma lógica de negociação diferente daquela observada nos casos de emissões realizadas no mercado de capitais. Essas emissões sucedem, não raro, de reuniões entre advogados e assessores financeiros dos envolvidos que negociam e estabelecem, em conjunto, as cláusulas da escritura de emissão antes de ela ser firmada pela companhia. $\mathrm{O}$ debenturista, aqui, influencia diretamente o conteúdo da escritura de forma a, consoante seu poder de barganha, proteger seus interesses no negócio entabulado por meio da emissão de debêntures, deixando de ser um mero aderente.

Esse aparente descompasso entre teoria e prática motivou a investigação sobre se o conteúdo da escritura de emissão de debêntures é, invariavelmente, reflexo da ausência de barganha entre companhia emissora e debenturista(s), conforme apresenta a doutrina comercialista atual. Para tanto, a análise da prática dos agentes de mercado se faz imprescindível para uma correta caracterização tanto da debênture como da escritura de emissão. Paula A. Forgioni ${ }^{4}$ continuamente nos ensinou que "[a] tradição do direito mercantil sempre pregou a indispensabilidade da observação do comportamento dos agentes econômicos, da sua prática”. Nesse sentido, “[a] compreensão da realidade é pressuposto do estudo comercialista [...]".

Todavia, o exaurimento dessa investigação em si não revelaria um desfecho prático à dissertação. Realizado o estudo, surgiria a indagação: quais os efeitos de o conteúdo da escritura de emissão ser ou não fruto de um processo de barganha entre os agentes envolvidos? Dessa questão emerge o objetivo central deste trabalho.

Diante da ausência de regras específicas ou mesmo de indícios doutrinários ou jurisprudenciais para a compreensão da escritura de emissão de debêntures, a proposição de elementos para a interpretação desse documento, que traz consigo termos e condições que regem os títulos emitidos, assume relevante papel para que se obtenha maior grau de segurança jurídica na verificação de sua licitude e de sua consonância com a intenção comum das partes envolvidas e com a finalidade econômica por elas pretendida.

Assim, esta dissertação tem como objetivo central apresentar as diretrizes gerais e específicas de interpretação de uma escritura de emissão de debêntures. No tocante às diretrizes gerais, este trabalho mostrará as razões para que a interpretação seja mais ou menos

FORGIONI, Paula A. A evolução do direito comercial brasileiro: da mercancia ao mercado. 2. ed. rev. e atual. São Paulo: RT, 2012. p. 26. 
adstrita ao conteúdo da escritura, considerando o contexto no qual a emissão de debêntures foi levada a efeito - se no âmbito privado ou público. Como diretrizes específicas, por sua vez, estudaremos o real alcance de determinadas normas previstas no Código Civil que dizem respeito à intepretação de negócios jurídicos, tendo como plano de aplicação: a noção comercial da escritura de emissão e o fato de o conteúdo da escritura ter sido ou não fruto de barganha entre os agentes. A partir dessa análise, entendemos ser possível expor importantes considerações concernentes à intepretação de uma escritura de emissão de debêntures visando proporcionar previsibilidade e segurança no manuseio desse instituto.

\subsection{Estruturação do trabalho considerando o objeto de pesquisa proposto}

Considerando o propósito científico adotado, este trabalho foi estruturado para que as questões essenciais que influem na interpretação da escritura de emissão sejam compreendidas. Dessa forma, será possível, ao final, assimilar as razões das diretrizes gerais e específicas que devem guiar a atividade do intérprete ao lidar com uma escritura de emissão de emissão de debêntures.

Inicialmente, o Capítulo 2, mediante breve análise da evolução históriconormativa, buscará apresentar que a disciplina jurídica da debênture sempre foi estruturada para regulá-la enquanto instrumento de captação de recursos de terceiros poupadores de maneira pública e despersonalizada no mercado. Diante dessa perspectiva do legislador, a doutrina pouco produziu a respeito das emissões privadas, muito embora sejam permitidas pela legislação e realizadas pelos agentes na prática. Após incursão sobre a posição dos doutrinadores diante de cada fase que compõe o procedimento para a emissão de debêntures, avançaremos ao principal objetivo desse capítulo: o estudo do contexto das operações privadas para diferenciá-lo daquele em que ocorrem emissões públicas. O exaurimento desse objetivo nos permitirá avançar ao estudo da debênture e da escritura de emissão munidos de uma premissa mais adstrita à realidade desses institutos.

Esclarecidos os contextos em que debêntures são emitidas pelos agentes econômicos, passaremos à caracterização da debênture no Capítulo 3. Esse objetivo será cumprido mediante a análise de dois de seus aspectos: sua função econômica e natureza jurídica. A investigação da função econômica se faz importante para compreender quais os motivos dos agentes no momento da emissão, isto é, qual sua intenção comum - importante vetor de interpretação de negócios empresariais. Pela análise da natureza jurídica, por outro lado, será possível delinear qual o regime jurídico aplicável ao título em cada caso. 
O Capítulo 4, por sua vez, tratará da caracterização da escritura de emissão de debêntures. Analisaremos, tal como realizado no Capítulo 3, sua função econômica e sua natureza jurídica. Nesse ponto, aprofundaremos nossas considerações para demonstrar as diferenças que podem existir entre uma escritura levada a efeito no mercado de capitais e outra na esfera privada entre agentes determinados. Como não há apreciações na doutrina ou na jurisprudência a respeito, examinaremos casos concretos para realçar essas diferenças e comprovar que, nem sempre, os debenturistas simplesmente aderirão aos termos e condições de uma escritura de emissão de debêntures ponderados e elaborados unilateralmente pela companhia emissora.

Principalmente com base nessa premissa, delinearemos as diretrizes gerais e específicas para a interpretação de uma escritura de emissão no Capítulo 5. Antes, estudaremos os limites à autonomia privada na elaboração da escritura impostos pela Lei das S.A. Feitas essas considerações - importantes para a verificação de validade -, apresentaremos, como diretrizes gerais, nossas razões para justificar uma interpretação mais restritiva ao texto de uma escritura de emissão pública em comparação àquela que rege uma emissão privada. Por fim, enquanto diretrizes específicas, examinaremos o alcance das normas dos arts. 112, 113, 422, 423 e 157, todos do Código Civil, reputando a natureza comercial da escritura e a possibilidade de seu conteúdo ter sido, ou não, fruto de barganha entre os agentes econômicos envolvidos na emissão.

\subsection{Justificativa e atualidade do tema}

Sobre a atualidade do tema, tivemos a oportunidade de comentar a crescente relevância da debênture ao financiamento das empresas brasileiras. Com o esgotamento dos recursos públicos para o financiamento de projetos de investimento de longo prazo, os quais já foram responsáveis por noventa por cento da carteira de crédito com vencimento superior a cinco $\operatorname{anos}^{5}$, a tendência é de observarmos um paulatino aumento de emissões

Nos termos da Exposição de Motivos da Medida Provisória n. ${ }^{\circ}$ 517, de 30 de dezembro de 2010, que posteriormente foi convertida na Lei Federal n. ${ }^{\circ} 12.431$, de 24 de junho de 2011, "o Governo e os bancos públicos, principalmente o BNDES, não podem continuar como promotores quase que exclusivos de tais recursos vis-à-vis o risco de minarmos nossa capacidade de sustentação do crescimento. Atualmente, quase noventa por cento da carteira de crédito com vencimento superior a cinco anos tem como lastro linhas oriundas de bancos públicos, sendo que só o BNDES é responsável por quase sessenta e dois por cento dessa carteira" (BRASIL. Medida Provisória n. ${ }^{\circ}$ 517, de 30 de dezembro de 2010. Diário Oficial da República Federativa do Brasil, 31 dez. 2010. Disponível em: http://www.planalto.gov.br/ ccivil_03/_ato2007-2010/2010/Exm/EMI-194-MF-MDIC-MC-MCT-MEC-MME-MP-MPV-517-10. htm. Acesso em: 18 maio 2018). Com efeito, Luciano CoutinHo, em artigo elaborado no ano de 2008, 
de debêntures no mercado brasileiro como fonte alternativa de funding. Além disso, alguns outros fatores militam para esse cenário: um movimento progressivo de redução das taxas de juros $^{6}$ e o reconhecimento da inadequação dos mecanismos típicos de financiamento bancário que majoritariamente focam operações de curto prazo. Ainda que o desenvolvimento do mercado de debêntures enfrente outros desafios de ordem microeconômica ${ }^{7}$, é possível notar um aumento de emissões no mercado de capitais.

Conforme o uso de debêntures se intensifique no Brasil, a demanda por formulações teóricas a respeito aumentará para que arestas que eventualmente surjam sejam aparadas e a emissão desses títulos se torne segura e previsível aos agentes. No entanto, ressaltamos que a questão das debêntures é relativamente escassa nos estudos monográficos. Daí a justificativa de abordar a debênture como tema com o propósito de colaborar com esse recente desenvolvimento do instituto no Brasil.

Dentro do tema macro de debênture existem institutos que ainda não foram abordados especificamente pela doutrina. A escritura de emissão é um deles. Trata-se de documento indispensável à emissão de debêntures e que contém as cláusulas que regem os títulos emitidos. Por essa razão, entendemos que a correta compreensão da escritura é um passo importante no caminho para a construção de um corpo doutrinário mais robusto a respeito da debênture, dado que, na hipótese de discussões judiciais ou arbitrais envolvendo esse título, os termos e condições que constarem da escritura exercerão papel central na solução do caso.

Logo, esta dissertação tem como propósito traçar algumas linhas acerca da interpretação de escritura de emissão sob a justificativa de que, ao assim procedermos,

apontou que, "[n]ão obstante as significativas transformações dos mercados de crédito e de capitais, o BNDES continua tendo um papel essencial no financiamento de longo prazo. Isso porque o mercado de crédito continua focado em operações de curto prazo: quase metade dos financiamentos tem prazo de até 180 dias. O mercado de capitais, por seu turno, tem se destinado a financiar, sobretudo, capital de giro para as empresas. De modo geral, como se observa no Gráfico 3, as atividades ligadas à expansão da capacidade produtiva - tais como aquisição de ativos, investimento em imobilizado e implantação de projetos - não são objeto de destino dos recursos captados nos mercados de capitais. Assim, para financiar seus investimentos, as empresas seguem recorrendo, primordialmente, à geração própria de caixa e aos financiamentos do BNDES" (COUTINHO, Luciano. O papel do BNDES na economia brasileira. Revista dos Tribunais Online, Rio de Janeiro, v. 41, p. 42-48, jul./set. 2008).

$6 \quad$ TORRES FILHO, Ennani Teixeira; MACAHYBA, Luiz. O elo perdido. O mercado de títulos de dívida corporativa no Brasil: avaliação e propostas. São Paulo: Instituto de Estudos para o Desenvolvimento Industrial - IEDi/Instituto Talento Brasil, 2012. Disponível em: http://retaguarda.iedi.org.br/midias/ artigos/4ff6e4934e2d3070.pdf. Acesso em: 21 abr. 2018.

7 YAZBEK, Otávio. A modernização do regime das debêntures e a criação de um mercado de dívida de longo prazo no Brasil, 2013, p. 569-572. 
será possível sistematizar os fundamentos jurídicos que subsidiem a atividade do intérprete tanto no tocante às escrituras celebradas em operações de emissões privadas como àquelas realizadas para reger emissões no mercado de capitais. O devido trato jurídico pelo intérprete é essencial para que haja segurança e previsibilidade na utilização da debênture pelos agentes econômicos, sobretudo em um cenário com poucas decisões judiciais a respeito e de pouca produção científica elaborada sobre o tema. 


\section{CAPÍTULO 6 \\ CONCLUSÕES}

A partir da análise empreendida, deve-se concluir que as operações privadas geram importantes efeitos para a interpretação de escrituras de emissão. Entretanto, ainda que permitido pela legislação e debêntures ser efetivamente lançadas no mercado, tanto no ambiente público como no privado, a doutrina pouco se debruçou sobre as diferenças existentes entre esses contextos e seus efeitos à caracterização desse título e da escritura de emissão, atentando-se mais aos casos de emissões no mercado de capitais.

Nesse sentido, podemos observar que a doutrina, em sua ampla maioria, aponta a debênture como um título de dívida a ser emitido em larga escala para possibilitar que o seu emitente capte grande monta de recursos perante inúmeros investidores. Por se tratar de negócio massificado, a escritura de emissão, componente do iter procedimental para a colocação desse título no mercado, é compreendida como um documento cujo conteúdo é unilateralmente concebido pela companhia emissora mediante adoção de cláusulas-modelo, cabendo aos interessados a mera adesão a esses termos propostos por meio da subscrição dos respectivos títulos.

Daí se tratar a relação de dívida entre emissora e debenturistas, estabelecida após a subscrição, como de um contrato de adesão. Com efeito, os custos de transação para que uma captação de recursos em massa ocorra não permitem a negociação entre companhia e interessados. Para tornar o negócio cabível, cabe à companhia conceber as regras do jogo dos títulos conforme a prática usual do mercado, observadas as normas mais rígidas de proteção ao investidor, e oferecê-los a um número indeterminado de interessados.

O ambiente privado, por sua vez, apresenta outra perspectiva. Trata-se de colocação de debêntures para um ou poucos agentes econômicos determinados. Aqui, os custos de transação são menores e os interesses dos debenturistas são mais concentrados, o que leva os agentes a barganhar os termos e as condições da escritura de emissão de debêntures antes de os títulos serem subscritos. Por essa razão, a autonomia privada neste contexto desfruta de maior espaço de atuação.

Nesse sentido, considerando sua natureza abstrata, as formas pelas quais podem ser ofertadas e a possibilidade legal de apresentarem qualidades próximas a de um título de participação, nem sempre as debêntures atuarão como valores mobiliários de dívida, 
tampouco será a relação entre companhia e debenturistas um contrato de adesão - muito embora legalmente caiba tão somente à companhia formalizar a escritura de emissão.

A análise dos casos concretos nos itens 4.4.1 e 4.4.2 ofereceu-nos substrato fático a respeito dessas considerações. Enquanto as debêntures emitidas por Rumo e Movida se apresentam como genuínos valores mobiliários de dívida, que são negociadas no mercado de capitais e garantem a seus detentores o pagamento de juros remuneratórios e amortização, as emitidas por $\mathrm{F}(\mathrm{X})$ e Redspark, em operações privadas e subscritas por um único debenturista, contêm qualidades extraordinárias que conferem a seu detentor poder de veto em matérias sensíveis à administração do negócio da emissora e a possibilidade de conversão dos títulos em participação no capital social com as bases do futuro acordo de acionistas já previamente acordadas.

Notam-se, de um lado, debêntures com qualidades genéricas de um título de dívida que circulará no mercado de capitais e, de outro, títulos especificamente criados para atender a uma particular finalidade econômica dos agentes envolvidos. Ademais, se o conteúdo das escrituras de emissão foi concebido unilateralmente por Rumo e Movida a partir do modelo da Anbima, os demais foram elaborados em conjunto entre companhia e debenturista e suas condições são fruto de um processo de barganha.

Apesar de não ser uma regra, é possível compreender que, entre um contexto e outro de oferta de debêntures, existe o privado que oferece um ambiente mais propício para que as partes ajustem as características da debênture e as condições da escritura de emissão consoante seus particulares interesses no caso concreto, podendo a finalidade econômica dos títulos e a relação entre companhia e debenturistas não se adequar ao que propaga boa parte da doutrina comercial a respeito do tema - haja vista que a lente de análise, na grande maioria das vezes, são apenas as operações públicas. Daí os importantes efeitos para a interpretação de escrituras de emissão que as operações privadas geram.

Sem se esquecer das diretrizes estabelecidas pela Lei das S.A. - sobretudo para a verificação da validade do pacto ou de determinada disposição -, entendemos, sob o panorama apresentado, que as disposições da escritura de emissão realizada para ofertar publicamente debêntures devem ser interpretadas e aplicadas de maneira mais restrita em comparação com as que regem emissão privada.

Isso porque, na grande maioria dos casos, essas condições emergirão de cláusulasmodelo objetivadas pelo mercado, abrindo as partes mão do exercício da autonomia privada em prol da previsibilidade decorrente da adoção dos usos e costumes vigentes. Assim, a 
preocupação do intérprete deverá centrar-se na finalidade e estrutura do negócio em si, pois costuma apresentar um alto nível de padronização, uma vez se tratar de um negócio de massa. Por seu turno, as escrituras de emissão privada de debêntures apresentam um grau de especificidade maior por disciplinarem interesses individuais. Eis a importância de se adotar uma interpretação subjetiva nesses casos, pois, além de levar as cláusulas da escritura em consideração, preocupa-se com os interesses, as intenções manifestadas e os comportamentos dos agentes que efetivaram o negócio.

As considerações apresentadas neste trabalho também interferem na aplicação dos artigos do Código Civil relacionados à interpretação dos negócios jurídicos às escrituras de emissão, considerando, ainda, sua natureza comercial. Para trabalharmos esse ponto, selecionamos os arts. 112, 113, 422, 423 e 157 do referido diploma legal, que tratam, respectivamente, da intenção nas declarações, da boa-fé e dos usos do lugar de celebração, da intepretação a favor do aderente e da lesão. Em primeiro lugar, para cada um desses artigos, harmonizamos a lente de análise para adequar sua aplicação a um instituto comercial, consoante as lições de PAUla A. Forgioni. Afinado esse entendimento, passamos a aplicá-lo às escrituras de emissão.

Com relação ao art. 112, o intérprete deve buscar a intenção comum das partes a partir da finalidade econômica pretendida com a emissão de debêntures. Nesse ponto, a principal consideração é que a debênture não cumprirá invariavelmente uma função de título de dívida. Como observado nos casos do item 4.4.2, esse título pode estabelecer direitos que se aproximam daqueles conferidos por títulos de participação. Nesse sentido, destaca-se que a escritura de emissão não regerá, única e exclusivamente, uma relação de intercâmbio de capital financeiro entre devedor e credor. É possível que haja casos em que o objetivo comum entre as partes pode construir uma dependência recíproca entre elas, emergindo com mais vigor a cooperação e seus deveres laterais para que o fim da emissão de debêntures seja exaurido.

A respeito da boa-fé e dos usos do lugar da celebração, consoante previsto pelos arts. 113 e 422 do Código Civil, deve o intérprete resguardar a aplicação da boa-fé objetivada conforme a prática usual do mercado. Para tanto, é preciso reconhecer que, enquanto os usos e costumes relacionados às colocações públicas de debêntures estão, no mais das vezes, incorporados nas próprias condições da escritura de emissão via utilização de cláusulasmodelo, os concernentes às operações privadas devem ser investigados caso a caso, dada a heterogeneidade das relações que pode ser estabelecida nesse contexto. 
Sobre a regra estampada no art. 423 do Código Civil, sua devida aplicação prescinde do reconhecimento da premissa de que existem diferentes contextos de emissão de debêntures. Se tomarmos referida regra para aplicação em benefício ao obrigado, e não ao aderente, é preciso compreender que, nos casos de emissões públicas, geralmente é o próprio obrigado - a companhia - que estabelece as condições da escritura de emissão. Nesse caso, não vislumbramos margem para aplicação do art. 423, eis que, do contrário, abrir-se-ia a possibilidade de reclamação do conteúdo obrigacional por aquele que as elaborou. Por outro lado, se assumirmos que existem casos em que os termos da escritura de emissão tenham emergido de um processo de barganha entre as partes, entendemos que poderá haver margem de interpretação mais favorável à companhia.

Ainda sobre o art. 423, a aplicação de sua regra em benefício do aderente exige do aplicador do Direito a assimilação da mesma premissa. Nem sempre o debenturista será um mero aderente ao conteúdo proposto unilateralmente pela companhia. Ainda que o seja, é preciso ter parcimônia em sua aplicação para que não haja uma "consumerização" da relação entre companhia e debenturistas, uma vez que estes subscrevem ou adquirem esses títulos no mercado de capitais para fins de investimento.

Por fim, para a aplicação do instituto da lesão, nos termos do art. 157 do Código Civil, deve o intérprete entender se o conteúdo da escritura de emissão é resultado de negociações entre os envolvidos ou se foi elaborado unilateralmente pela companhia. Nesta última hipótese, compreendemos não ser possível a aplicação da lesão. No primeiro, entretanto, pode haver situações em que a companhia assumirá obrigações manifestamente desproporcionais, sobretudo nos casos em que apresentar grave situação econômicofinanceira. Por outro lado, deve-se sopesar que as cláusulas da escritura de emissão exercem uma função especial de proteção ao crédito e seu rigor dependerá do risco de inadimplemento que a emissora apresentar. Assim, deve esse dispositivo legal ser delicadamente dosado no caso, devendo sua aplicação mirar nas circunstâncias de claro e evidente abuso de direito, para não desvirtuar a finalidade econômica dos títulos.

Diante dessas considerações, conclui-se que a debênture e a escritura de emissões apresentam nuances capazes de influenciar e alterar o modo de sua interpretação. Nosso propósito foi expor algumas dessas particularidades, ainda não enfrentadas de maneira específica pela doutrina ou por tribunais, e destacar seus efeitos ao aplicador do Direito. Considerando um cenário com poucas decisões judiciais a respeito e de pouca produção científica elaborada sobre o tema, buscou-se uma sistematização dos fundamentos jurídicos para subsidiar a atividade do intérprete, tanto no tocante às escrituras celebradas em operações 
de emissões privadas como àquelas realizadas para reger emissões no mercado de capitais, de modo a subjugar o fundamento econômico dessas operações e estabelecer segurança e previsibilidade na utilização da debênture, independentemente de seu contexto de emissão. 


\section{REFERÊNCIAS}

ABAMEC. III Seminário - Debêntures e sua importância no mercado de capitais brasileiro. São Paulo, maio 1982.

ABREU, Ari Ferreira de. Um estudo sobre a estrutura de capital e a política de dividendos considerando a tributação brasileira. 2004. 216 f. Dissertação (Mestrado) - Universidade de São Paulo, São Paulo: FEA/USP, 2004.

AKIRA, Chinen. Commercial paper: novo título de valor mobiliário no processo de globalização da econômica. São Paulo: Atlas, 1996.

AMARAL, José Romeu Garcia do. Regime jurídico das debêntures. 2. ed. São Paulo: Almedina, 2016.

ASCARELLI, Tullio. Panorama do direito comercial. Sorocaba: Minelli, 2005.

ASCARELLI, Tullio. Teoria geral dos títulos de crédito. Campinas: Servanda, 2009.

ASSOCIAÇÃO Nacional das Entidades dos Mercados Financeiro e de Capitais - Anbima. Boletim de Mercado de Capitais, maio 2018. Disponível em: http://www.anbima.com.br/pt br/informar/relatorios/mercado-de-capitais/boletim-de-mercado-de-capitais/. Acesso em: 27 jun. 2018.

ASSOCIAÇÃO Nacional das Entidades dos Mercados Financeiro e de Capitais - Anbima. Guia Anbima. Orientação para Escrituras de Debêntures. São Paulo: Anbima, 2015. Disponível em: http://www.anbima.com.br/data/files/60/87/91/E9/602085106351AF7569A80AC2/ GuiadeOrientacaoparaEscriturasdeDebentures-29-10-15_1_.pdf. Acesso em: 3 jul. 2018.

AZEVEDO, Antônio Junqueira de. Negócio jurídico: existência, validade e eficácia. 4. ed. atual. de acordo com o novo Código Civil (Lei n. 10.406, de 10.01.2002. São Paulo: Saraiva, 2002.

BARBOSA FILHO, Marcelo Fortes. Sociedade anônima atual: comentários e anotações às inovações trazidas pela Lei n. ${ }^{\circ} 10.303 / 01$ ao texto da Lei n. ${ }^{\circ}$ 6.404/76. São Paulo: Atlas, 2004.

BARROS MONTEIRO, Washington de. Curso de direito civil. Direito das obrigações. 4. ed. São Paulo: Saraiva, 1965. v. 2.

BORBA, José Edwaldo Tavares. Das debêntures. Rio de Janeiro: Renovar, 2005.

BORBA, José Edwaldo Tavares. Direito societário. 14. ed. São Paulo: Atlas, 2015. 
BORGES, José Eunápio. Títulos de crédito. 2. ed. Rio de Janeiro: Forense, 1971.

BORGES, Luiz Ferreira Xavier. Covenants - instrumento de garantia em project finance. Revista dos Tribunais Online, Rio de Janeiro, v. 5, p. 123-135, maio/ago. 1999.

BRASIL. Comissão de Valores Mobiliários. Processo Administrativo CVM n. ${ }^{\circ}$ RJ 2003/0499. Relator: Diretor Luiz Antonio de Sampaio Campos. Julgamento: 28.08.2003.

BRASIL. Comissão de Valores Mobiliários. Processo Administrativo CVM RJ n. ${ }^{\circ}$ 2005/4105. Relator: Diretor Wladimir Castelo Branco Castro. Julgamento: 06.12.2005.

BRASIL. Medida Provisória n. ${ }^{\circ}$ 517, de 30 de dezembro de 2010. Diário Oficial da República Federativa do Brasil, 31 dez. 2010. Disponível em: http://www.planalto.gov.br/ccivil_03/_ ato2007-2010/2010/Exm/EMI-194-MF-MDIC-MC-MCT-MEC-MME-MP-MPV-517-10. htm. Acesso em: 18 maio 2018.

BRASIL. Superior Tribunal de Justiça. REsp n.$^{\circ}$ 784.881/CE. Terceira Turma. Ministro Relator: Carlos Alberto Menezes Direito. Julgamento: 04.05.2006. Data de publicação: 18.12.2006.

BRASIL. Superior Tribunal de Justiça. REsp n. ${ }^{\circ}$ 1.162.117/SP. Quarta Turma. Ministro Relator: João Otávio de Noronha. Julgamento: 04.09.2012. Data de publicação: 20.11.2014.

BRASIL. Tribunal de Justiça do Estado de São Paulo. Agravo de Instrumento n. ${ }^{\circ} 2223455$ 49.2018.8.26.0000. 2. ${ }^{\mathrm{a}}$ Câmara Reservada de Direito Empresarial. Foro Central Cível - 2. ${ }^{\mathrm{a}}$ Vara de Falências e Recuperações Judiciais. Relator: Des. Ricardo Negrão. Julgamento: 25.02.2019. Data de Registro: 27.02.2019.

BULGARELLI, Waldirio. Manual das sociedades anônimas. 2. ed. São Paulo: Atlas, 1980. BULGARELLI, Waldirio. Questões de direito societário. São Paulo: RT, 1983.

CANTIDIANO, Luiz Leonardo. Emissão pública de debêntures por sociedade de propósito específico. Utilização dos recursos captados na citada emissão para antecipar, a clube de investimentos de empregados do sistema Telebras, recursos correspondentes ao valor das ações adquiridas no processo de privatização da Telebras. Estruturação da operação. In: CANTIDIANO, Luiz Leonardo. Estudos de direito societário. Rio de Janeiro: Renovar, 1999. p. 103-116.

CARVALHO DE MENDONÇA, José Xavier. Tratado de direito comercial brasileiro. 2. ed. Rio de Janeiro: Livraria Freitas Bastos, 1934. v. IV, Livro II.

CARVALHOSA, Modesto; KUYVEN Fernando. Sociedades anônimas. São Paulo: RT, 2018. v. III. (Coleção Tratado de direito empresarial.) 
CASTRO, Hélio Oliveira Portocarrero de (coord.). Introdução ao mercado de capitais. Coordenação. Rio de Janeiro: IBMEC, 1979.

CODORNIZ, Gabriela; PATELlA, Laura (coord.). Comentários à Lei do Mercado de Capitais: Lei n. ${ }^{\circ}$ 6.385/76. São Paulo: Quartier Latin, 2015.

COELHO, Fábio Ulhoa. Curso de direito comercial. 8. ed. São Paulo: Saraiva, 2005. v. 2.

COMPARATO, Fábio Konder. Anatureza da sociedade anônima e a questão da derrogabilidade das regras legais de quórum nas assembleias gerais e reuniões do conselho de administração. In: COMPARATO, Fábio Konder. Novos ensaios e pareceres de direito empresarial. Rio de Janeiro: Forense, 1981.

COMPARATO, Fábio Konder. As ações de sociedade anônima como valores mobiliários natureza e efeitos do registro acionário. In: COMPARATO, Fábio Konder. Novos ensaios e pareceres de direito empresarial. Rio de Janeiro: Forense, 1981.

COMPARATO, Fábio Konder. Direito empresarial: estudos e pareceres. São Paulo: Saraiva, 1995.

COMPARATO, Fábio Konder; SALOMÃO FILHO, Calixto. O poder de controle na sociedade anônima. 6. ed. rev. e atual. Rio de Janeiro: Forense, 2014.

COUTINHO, Luciano. O papel do BNDES na economia brasileira. Revista dos Tribunais Online, Rio de Janeiro, v. 41, p. 42-48, jul./set. 2008.

COUTO E SILVA, Clóvis V. do. A obrigação como processo. Rio de Janeiro: Editora FGV, 2006.

CRAVEIRO, Mariana Conti. Contrato entre sócios: interpretação e direito societário. São Paulo: Quartier Latin, 2013.

CVM. Nota explicativa à Instrução CVM n. ${ }^{\circ}$ 404, de 13 de fevereiro de 2004. Disponível em: http://www.cvm.gov.br/export/sites/cvm/legislacao/notas-explicativas/anexos/nota404. pdf. Acesso em: 27 jul. 2019.

DE CHIARA, José Tadeu. Debêntures. In: MARTINS, Ives Gandra da Silva; VIDIGAL, Geraldo de Camargo (coord.). Comentários à Lei das Sociedades por Ações: Lei 6.404/76. São Paulo: Resenha Universitária/Instituto de Advogados de São Paulo, 1978. v. 5.

DINIZ, Gustavo Saad. Instrumentos de capitalização societária. Revista de Direito Privado, São Paulo, v. 49, p. 6, jan./mar. 2012.

DINIZ, Gustavo Saad. Instrumentos de capitalização societária. São Paulo: LiberArs, 2014. 
DINIZ, Maria Helena. Curso de direito civil brasileiro: direito de empresa. São Paulo: Saraiva, 2008. v. 8.

EIZIRIK, Nelson. Aspectos modernos do direito societário. Rio de Janeiro: Renovar, 1992.

EIZIRIK, Nelson. Debêntures. Prazo de prescrição para cobrança judicial. In: YARSHELL, Luiz Flavio; PEREIRA, Guilherme Setoguti J. (coord.). Processo societário. São Paulo: Quartier Latin, 2015. v. II, p. 387-400.

EIZIRIK, Nelson. Lei das S.A. comentada. São Paulo: Quartier Latin, 2011. v. I.

EIZIRIK, Nelson; GAAL, Ariádna B.; PARENTE, Flávia; HENRIQUES, Marcus de Freitas. Mercado de capitais: regime jurídico. 3. ed. rev. e ampl. Rio de Janeiro: Renovar, 2011.

FACHIN, Luiz Edson. Boa-fé como itinerário do processo obrigacional, inexigibilidade de dívida e ausência de causa. Revista dos Tribunais Online, v. 1, p. 57-89, jan. 2012.

FERREIRA, Waldemar Martins. Tratado das debênturas. Rio de Janeiro: Livraria Freitas Bastos, 1944. v. 1.

FERREIRA, Waldemar Martins. Tratado de sociedades mercantis. 4. ed. rev. e aum. Rio de Janeiro: Livraria Freitas Bastos, 1952. v. 3.

FORGIONI, Paula A. A evolução do direito comercial brasileiro: da mercancia ao mercado. 2. ed. rev. e atual. São Paulo: RT, 2012.

FORGIONI, Paula A. A interpretação dos negócios empresariais no novo Código Civil brasileiro. Revista de Direito Mercantil, Industrial, Econômico e Financeiro, São Paulo, ano XLII, Nova Série, n. 130, abr./jun. 2003.

FORGIONI, Paula A. Contratos empresariais: teoria geral e aplicação. 3. ed. São Paulo: Thomson Reuters Brasil, 2018.

FREITAS, Bernardo Vianna. Fundos de investimento em participações (FIP) e Fundos mútuos de investimento em empresas emergentes (FMIEE). In: FREITAS, Bernardo Vianna; VERSIANI, Fernanda Valle (coord.). Fundos de investimentos: aspectos jurídicos, regulamentares e tributários. São Paulo: Quartier Latin, 2015. p. 161.

GOMES, Orlando. Contratos. 4. ed. Rio de Janeiro: Forense, 1973.

GONÇALVES NETO, Alfredo de Assis. Manual das companhias ou sociedades anônimas. 2. ed. São Paulo: RT, 2010.

GRAU, Eros Roberto. Ensaio e discurso sobre a interpretação/aplicação do direito. 2. ed. São Paulo: Malheiros, 2003. 
GRAU, Eros Roberto; FORGIONI, Paula A. O Estado, a empresa e o contrato. São Paulo: Malheiros, 2005.

GUERREIRO, José Alexandre Tavares. Sociedade anônima-Assembleia geral extraordinária de debêntures - Emissão - Conversão em ações preferenciais com e sem direito de voto - Direito de recesso dos acionistas minoritários. Revista de Direito Mercantil, Industrial, Econômico e Financeiro, São Paulo, ano XXIII, n. 93, p. 114-122, jan./mar. 1994.

GUIMARÃES, Francisco José Pinheiro. Debêntures. In: LAMY FILHO, Alfredo; BULHÕES PEDREIRA, José Luiz (coord.). Direito das companhias. 2. ed. atual. e ref. Rio de Janeiro: Forense, 2017. Capítulo IV.

KRAAKMAN, Reinier;ARMOUR, John; DAVIES, Paul; ENRIQUES, Luca; HANSMANN; Henry; HERTIG, Gerard; HOPT, Klaus; KANDA, Hideki; PARGENDLER, Mariana; RINGE, Wolf-Georg; ROCK, Edward. The anatomy of corporate law. A comparative and functional approach. $3^{\text {rd }}$ ed. Oxford: Oxford University Press, 2017.

LAMY FILHO, Alfredo; PEDREIRA, José Luiz Bulhões. Direito das companhias. 2. ed. atual. e ref. Rio de Janeiro: Forense, 2017.

LEÃES, Luiz Gastão Paes de Barros. A conversão de debêntures em ações e o correspondente aumento do capital social. In: LEÃES, Luiz Gastão Paes de Barros. Pareceres. São Paulo: Singular, 2004. v. I, p. 99-115.

LEÃES, Luiz Gastão Paes de Barros. Comentários à Lei das Sociedades Anônimas. São Paulo: Saraiva, 1978. v. 2.

LEÃES, Luiz Gastão Paes de Barros. Debêntures. In: LEÃES, Luiz Gastão Paes de Barros. Estudos e pareceres sobre sociedades anônimas. São Paulo: RT, 1989. p. 82-94.

LEÃES, Luiz Gastão Paes de Barros. Pareceres. São Paulo: Singular, 2004.

LORIA, Eli. Alterações da lei societária pela Lei 12.431/2011. Revista dos Tribunais Online, Rio de Janeiro, v. 53, p. 211-225, jul./ago. 2011.

LUCCA, Newton de. Aspectos da teoria geral dos títulos de crédito. São Paulo: Pioneira, 1979.

LUCENA, José Waldecy. Das sociedades anônimas. Comentários à lei. Rio de Janeiro: Renovar, 2009. v. I.

MACEY, Jonathan R.; ENRIQUES, Luca. Creditors versus capital formation: the case against the European legal capital rules. Faculty Scholarship Series. Paper 1413, 2001. Disponível em: http://digitalcommons.law.yale.edu/fss_papers/1413. Acesso em: 11 jul. 2019. 
MARINO, Francisco Paulo de Crescenzo. Interpretação do negócio jurídico. São Paulo: Saraiva, 2011.

MARQUES, Evy Cynthia. A proteção aos credores na Lei n. 6.404/76: análise específica de alguns mecanismos. 2016. 279 f. Tese (Doutorado em Direito) - Universidade de São Paulo, São Paulo, 2016.

MARTINS, Eliseu; LOPES, Alexsandro Broedel. Contabilização de debêntures perpétuas com participação nos lucros. O caso "Tec Toy". Revista de Direito Mercantil, Industrial, Econômico e Financeiro, São Paulo, Nova Série, ano L, n. 158, p. 267-279, abr./jun. 2011.

MARTINS, Fran. Comentários à Lei das Sociedades Anônimas. Artigos 1. o a 105. Rio de Janeiro: Forense, 1977. v. I.

MARTINS, Frans. Contratos e obrigações comerciais. 8. ed. rev. e aum. Rio de Janeiro: Forense, 1986.

MATTOS FILHO, Ary Oswaldo. Conceito de valor mobiliário. Revista de Direito Mercantil, Industrial, Econômico e Financeiro, São Paulo, n. 59, set. 1986.

MATTOS FILHO, Ary Oswaldo. Direito dos valores mobiliários. Rio de Janeiro: FGV, 2015. v. I, t. 2.

MENDES, Octavio. Da posição juridica do debenturista em face da fallencia. 1919. Dissertação (Mestrado) - Faculdade de Direito de São Paulo, São Paulo, 1919.

MENDES, Octavio. Dos títulos de crédito. São Paulo: Livraria Academica, 1931.

MIRANDA, Custódio da Piedade Ubaldino. Interpretação e integração dos negócios jurídicos. São Paulo: RT, 1989.

MOREIRA DA SILVA, Fernando César Nimer. Venture capital: valor da informação, riscos e instrumentos para sua mitigação. 2014, 178 f. Tese (Doutorado) - Faculdade de Direito, Universidade de São Paulo, São Paulo, 2014.

MOTTA, Rita de Cássia Luz Teixeira. O conceito de valor mobiliário no direito brasileiro. 2002. Dissertação (Mestrado em Direito Econômico) - Faculdade de Direito, Universidade de São Paulo, São Paulo, 2002.

NAKASONE, William Joji. O financiamento de inovações por meio do venture capital: adequação dos instrumentos jurídicos brasileiros. 2013. 133 f. Dissertação (Mestrado) Faculdade de Direito, Universidade de São Paulo, São Paulo.

PINTO JR., Mario Engler. Debêntures. Direitos de debenturistas. Comunhão e assembleia. Agente fiduciário. Revista de Direito Mercantil, Industrial, Econômico e Financeiro, São Paulo, ano XXI, n. 48, p. 25-37, out./dez. 1982. 
PITTA, André Grüspun. A possibilidade de emissão de debêntures por sociedade limitada regida supletivamente pela Lei das Sociedades por Ações. In: AZEVEDO, Luís André N. de Moura; CASTRO, Rodrigo R. Monteiro de (coord.). Sociedade limitada contemporânea. São Paulo: Quartier Latin, 2013. (Coleção IDSA.)

PITTA, André Grüspun. A problemática intersecção entre títulos de crédito e valores mobiliários. Revista dos Tribunais Online, Rio de Janeiro, v. 6, p. 111-132, jul./ago. 2014.

PONTES DE MIRANDA, Francisco Cavalcanti. Tratado de direito cambiário. Letra de câmbio. São Paulo: Max Limonad, 1954. v. I.

PONTES DE MIRANDA, Francisco Cavalcanti. Tratado de direito privado. Parte Especial. Direito das Obrigações. Títulos ao portador (continuação). Títulos nominativos. Títulos endossáveis. Atualizado por: Alcides Tomasetti Jr. e Rafael Domingos Faiardo Vanzella. São Paulo: RT, 2012. t. XXXIII.

REQUIÃO, Rubens. Curso de direito comercial. São Paulo: Saraiva, 2003. v. 2.

RIGER, Martin. The trust indenture as bargained contract: the persistence of myth. Delaware Journal of Corporate Law, v. 16, n. 211, p. 216, 1991.

ROCCA, Carlos. Financiamento do investimento no Brasil e o papel do mercado de capitais. In: ALMEIDA, Julio Sergio Gomes de; CAGNIN, Rafael Fagundes (org.). BNDES, mercado de capitais e o financiamento de longo prazo no Brasil. São Paulo: Instituto de Estudos para o Desenvolvimento Industrial - IEDI, 2018. Disponível em: https://www.iedi.org.br/media/ site/artigos/20181128_bndes.pdf. Acesso em: 7 jul. 2019.

RODRÍGUEZ, Luis de Angulo. La financiación de empresas mediante tipos especiales de obligaciones. Bologna: Publicaciones del Real Colegio de Espanã en Bolonia, 1968.

RUSSEL, Alfredo. Curso de direito commercial brasileiro. Rio de Janeiro: Livraria Scientifica Brasileira Süssekind de Mendonça \& Cia, 1924. t. II.

SALLES, Marcos Paulo de Almeida. Uma contribuição ao estudo das debêntures. 1986. 205 f. Dissertação (Mestrado em Direito) - Universidade de São Paulo, São Paulo, 1986.

SALOMÃO FILHO, Calixto. Breves acenos para uma análise estruturalista do contrato. Revista de Direito Mercantil, Industrial, Econômico e Financeiro, São Paulo, v. 141, jan./ mar. 2006.

SALOMÃO NETO, Eduardo. Direito bancário. São Paulo: Atlas, 2011.

SCHAPIRO, Mario Gomes. Novos parâmetros para a intervenção do Estado na economia: persistência e dinâmica na atuação do BNDES em uma economia baseada no conhecimento. 2009. 326 f. Tese (Doutorado em Direito) - Universidade de São Paulo, São Paulo. 
SHADAB, Houman B. Interpreting indentures: how disequilibrium economics and financial asset specificity support narrow interpretation. Southern California Law Review, v. 75, n. 3, p. 763-790, Mar. 2002.

SILVA, Leonardo Toledo da. Contratos de aliança. Direito empresarial e ambiente cooperativo. 2014. 384 f. Tese (Doutorado) - Faculdade de Direito, Universidade de São Paulo, São Paulo, 2014

SOUZA, H. Inglez de. Títulos ao portador no direito brasileiro. Rio de Janeiro: Livraria Francisco Alves, 1898.

SZTAJN, Rachel. Conceito de liquidez na disciplina do mercado de valores mobiliários. Revista de Direito Mercantil, Industrial, Econômico e Financeiro, São Paulo, Nova Série, ano XLI, n. 126, p. 19, 2002.

TEIXEIRA, Egberto Lacerda. A conversão de debêntures em ações e o aumento do capital social. Revista de Direito Mercantil, Industrial, Econômico e Financeiro, São Paulo, ano XXIII, n. 54, p. 131-133, 1984.

TEIXEIRA, Egberto Lacerda; GUERREIRO, José Alexandre Tavares. Das sociedades anônimas no direito brasileiro. São Paulo: Bushatsky, 1979. v. I.

TORRES FILHO, Ernani Teixeira; MACAHYBA, Luiz. O elo perdido. O mercado de títulos de dívida corporativa no Brasil: avaliação e propostas. São Paulo: Instituto de Estudos para o Desenvolvimento Industrial - Iedi/Instituto Talento Brasil, 2012. Disponível em: http:// retaguarda.iedi.org.br/midias/artigos/4ff6e4934e2d3070.pdf. Acesso em: 27 jun. 2018.

TUNG, Frederick. Leverage in the board room: the unsung influence of private lenders in corporate governance governance. UCLA Law Review, v. 57, Issue 1, p. 115-182, May 2009. Emory Public Law Research Paper, n. 9-54; Emory Law and Economics Research Paper, n. 9-43. Disponível em: https://ssrn.com/abstract=1356662. Acesso em: 4 set. 2018.

VALVERDE, Trajano de Miranda. Sociedades por ações. Comentários ao Decreto-lei n. ${ }^{\circ}$ 2.627, de 26 de setembro de 1940. Rio de Janeiro: Forense, 1942. v. I.

VIVANTE, Cesare. Trattato di diritto commerciale. 5. ed. 3. reimpr. Milano: Vallardi, 1934. v. III.

VIDIGAL, Geraldo de Camargo; MARTINS, Ives Gandra da Silva (coord.). Comentários à Lei das Sociedades por Ações: Lei n. ${ }^{\circ}$ 6.404/76. São Paulo: Ed. Resenha Universitária, Instituto dos Advogados de São Paulo, 1978.

WALD, Arnoldo. O regime jurídico da comunhão de debenturistas e as condições de validade e oponibilidade das deliberações assembleares. Revista de Direito Mercantil, Industrial, Econômico e Financeiro, São Paulo, ano XXXIII, n. 94, p. 5-12, abr.jun. 1994. 
YAZBEK, Otávio. A modernização do regime das debêntures e a criação de um mercado de dívida de longo prazo no Brasil. In: CASTRO, Rodrigo R. Monteiro et al. (coord.). Direito empresarial e outros estudos de direito em homenagem ao Professor José Alexandre Tavares Guerreiro. São Paulo: Quartier Latin, 2013.

YAZBEK, Otávio. Regulação do mercado financeiro e de capitais. 2. ed. Rio de Janeiro: Elsevier, 2009.

\section{Referências complementares}

ALMEIDA, Júlio Sergio Gomes de; CINTRA, Marcos Antonio Macedo; JACOB, Claudio Avanian; NOVAIS, Luis Fernando; FILLETI, Juliana de Paula. Padrões de financiamento das empresas: a experiência brasileira. In: CINTRA, Marcos Antonio Macedo; SILVA FILHO, Edison Benedito da (org.). Financiamento das corporações: perspectivas do desenvolvimento brasileiro. Brasília: Ipea, 2013.

AMARAL, José Romeu Garcia do.; STÊNICO, Rodrigo Nacarato. Sobre a tutela dos debenturistas em juízo. In: YARSHELL, Flávio Luiz; PEREIRA, Guilherme Setoguti J. (ccord.). Processo societário. São Paulo: Quartier Latin, 2015. v. II.

ARIDA, Persio; BACHA, Edmar Lisboa; LARA-RESENDE, André. Credit, interest, and jurisdictional uncertainty: conjectures on the case of Brazil. In: GIAVAZZI, Francesco; GOLDFAJN, Ilan; HERRERA, Santiago. Inflation targeting, debt, and the Brazilian experience, 1999 to 2003. Cambridge: The MIT Press, 2005.

ASCARELLI, Tullio. Problemas das sociedades anônimas e direito comparado. São Paulo: Quorum, 2008.

ASSOCIAÇÃO Nacional das Entidades dos Mercados Financeiro e de Capitais - Anbima. Proposta para a ampliação e o alongamento de prazos no mercado de títulos privados de renda fixa no Brasil. São Paulo: Anbima, 2011.

BITTAR, Carlos Alberto. Direito das obrigações. 2 ed., rev., atual. e ampl. de acordo com o novo Código Civil. Rio de Janeiro: Forense Universitária, 2004.

BORBA, José Edwaldo Tavares. Debêntures. Revista de Direito Mercantil, Industrial, Econômico e Financeiro, São Paulo, ano XVI, n. 26, p. 135-151, 1977.

BRUDNEY, Victor; CHIRELSTEIN, Marvin A. Cases and materials on corporate finance. $2^{\text {nd }}$ ed. Mineola: The Foundation Press, 1979.

BULGARELLI, Waldírio. Contratos mercantis. 14. ed. São Paulo: Atlas, 2001. 
BULGARELLI, Waldírio. Títulos de crédito. 2. ed. rev. e atual. São Paulo: Atlas, 1982.

CAMPANA FILHO, Fernando. Assembleia dos debenturistas e problemas relacionados ao direito de voto. In: NOVAES FRANÇA, Erasmo Valadão Azevedo e (org.). Direito societário contemporâneo II. São Paulo: Malheiros, 2015.

CAMPBELL JR., Rutherford B. Manager's fiduciary duties in financially distressed corporations: chaos in delaware (and elsewhere). Journal of Corporation Law, v. 32, Issue 3, p. 491-528, Spring 2007.

COMPARATO, Fábio Konder. As ações de sociedade anônima como valores mobiliários natureza e efeitos do registro acionário. In: COMPARATO, Fábio Konder. Novos ensaios e pareceres de direito empresarial. Rio de Janeiro: Forense, 1981.

COMPARATO, Fábio Konder. Restrições à circulação de ações em companhia fechada: nova et vetera. In: COMPARATO, Fábio Konder. Novos ensaios e pareceres de direito empresarial. Rio de Janeiro: Forense, 1981.

CUNHA, Luciana Gross. Segurança jurídica: performance das instituições e desenvolvimento. In: CUNHA, Luciana Gross. Poder Judiciário e desenvolvimento do mercado de valores mobiliários brasileiro. São Paulo: Saraiva, 2008. p. 131-143.

CUNHA, Rodrigo Ferraz Pimenta da. Estrutura de interesses nas sociedades anônimas: hierarquia e conflitos. São Paulo: Quartier Latin, 2007.

DINIZ, Gustavo Saad. Estudos e pareceres de pessoas jurídicas e da atividade empresarial. São Paulo: LiberArs, 2013.

FERREIRA, Waldemar. Instituições de direito comercial. Rio de Janeiro: Livraria Freitas de Bastos, 1953.

FERREIRA, Waldemar. Questões de direito comercial (pareceres). Segunda série. São Paulo: Typographia Siqueira, 1932.

FREITAS, Maria Cristina Penido de. Financiamento de longo prazo no Brasil: avanços e desafios. In: CINTRA, Marcos Antonio Macedo; SILVA FILHO, Edison Benedito da (org.). Financiamento das corporações: perspectivas do desenvolvimento brasileiro. Brasília: Ipea, 2013.

GOMES, Orlando. Obrigações. 8. ed. Rio de Janeiro: Forense, 1988.

GUERREIRO, José Alexandre Tavares. Problemas atuais das debêntures. Revista de Direito Mercantil, Industrial, Econômico e Financeiro, São Paulo, ano XXII, n. 52, p. 128-135, out./ dez. 1983. 
HAMILTON, Robert W. The law of corporations in a nutshell. St. Paul, Minn.: West Publishing Co., 1996.

KIRSCHBAUM, Deborah. Recuperação judicial e governança corporativa: a relação entre a disciplina jurídica da insolvência e a governança das empresas de grande e médio portes no Brasil. In: LIMA, Maria Lúcia L. M. Pádua (coord.). Agenda contemporânea. Direito e economia: 30 anos de Brasil. São Paulo: Saraiva, 2012. t. 3, p. 290-325.

KUMAR, Anjali; FRANCISCO, Manuela. Enterprise size, financing patterns and credit constraints in Brazil: analysis of data from the investment climate assessment survey. World Bank Working Paper, n. 49. Disponível em: http://ssrn.com/abstract=960152. Acesso em: 27 jun. 2018.

LACERDA, J. C. Sampaio de. Noções fundamentais sôbre sociedades anônimas. Rio de Janeiro: Editora Nacional de Direito, 1956.

LAZZARESCHI NETO, Alfredo Sergio. Lei das sociedades por ações anotada. 4. ed. rev., atual. e ampl. São Paulo: Saraiva, 2012.

MOREIRA, Maurício Mesquita; PUGA, Fernando Pimentel. Como a indústria financia o seu crescimento. Uma análise do Brasil pós-real. Revista de Economia Temporânea, v. 5, Edição Especial, 2000.

MOSQUERA, Roberto Quiroga (coord.). Aspectos atuais do direito do mercado financeiro e de capitais. São Paulo: Dialética, 1999.

MUSSNICH, Francisco Antunes Maciel. As recentes alterações com respeito à competência para emissão de debêntures. In: CASTRO, Rodrigo R. Monteiro et al. (coord.). Direito empresarial e outros estudos de direito em homenagem ao Professor José Alexandre Tavares Guerreiro. São Paulo: Quartier Latin, 2013.

PARK, James J. Bondholders and securities class actions. Minnesota Law Review, v. 99, Issue 2, p. 585-648, Dec. 2014.

PARTNOY, Frank. Financial innovation in corporate law. Journal of Corporation Law, v. 31, Issue 3, p. 799-828, Spring 2006.

PAULA, Luiz de. Debêntures (obrigações). São Paulo: Livraria Editôra, 1971.

PINHEIRO, Juliano Lima. Mercado de capitais: fundamentos e técnicas. 4. ed. São Paulo: Atlas, 2007.

PRADO, Viviane Muller. Reflexões sobre enforcement de normas societárias. In: PRADO, Viviane Muller. Poder Judiciário e desenvolvimento do mercado de valores mobiliários brasileiro. São Paulo: Saraiva, 2008. p. 115-129. 
ROCCA, Carlos Antônio; SANTOS JUNIOR, Lauro Modesto; PAES, Marly; FUMAGALLI, Fernando. M. Relatório Trimestral de Financiamento dos Investimentos no Brasil. Nota CEMEC 05/2017. Instituto IBMEC. Centro de Estudos IBMEC, jun. 2017. Disponível em: http://codemec.org.br/instituto/wp-content/uploads/2014/10/NOTA-CEMEC-05-2017PADRAO-DE-FINANCIAMENTO-DOS-INVESTIMENTOS.pdf. Acesso em: 3 jul. 2018.

RODRIGUES JÚNIOR, Waldery; MELO, Giovani Monteiro. Padrão de financiamento das empresas privadas no Brasil. Texto para discussão, Brasília, n. 653, jun. 1999. Disponível em: http://www.ipea.gov.br/agencia/images/stories/PDFs/TDs/td_0653.pdf. Acesso em: 27 jun. 2018.

ROMANO, Roberta. Foundations of corporate law. New York: Foudation Press, 1993.

ROSS, Stephen A.; WESTERFIELD, W. Randolph; JEFFREY, F. Jaffe. Administração financeira: corporate finance. Tradução Antonio Zoratto Sanvicente. São Paulo: Atlas, 1995.

SANTOS, J. A. Penalva. Sociedade anônima - Decurso do prazo prescricional ao exercício do direito à percepção das vantagens em favor do debenturista. Revista de Direito Mercantil, Industrial, Econômico e Financeiro, São Paulo, ano XL, n. 124, p. 81-84, out./dez. 2001.

SILVA, André Luiz Carvalhal da; LEAL, Ricardo Pereira Câmara. O mercado de títulos privados de renda fixa no Brasil. Relatório econômico. Rio de Janeiro: Andima/Coppead, 2008.

SINGH, Ajit. Corporate financial patterns in industrializing economies: a comparative international study. International Finance Corporation Technical Paper, n. 2, IFC Working Paper Series. Washington, D.C.: The World Bank. Disponível em: http://documents. worldbank.org/curated/en/858011468739577096/Corporate-financial-patterns-inindustrializing-economies-a-comparative-international-study. Acesso em: 1. o jul. 2018.

STIGLITZ, Joseph. Government, financial markets and economic development. Working Paper, n. 3669, National Bureau of Economic Research, 1991.

TAGGART, Robert A. A model of corporate financing decisions. The Journal of Finance, v. 32, n. 5, p. 1467-1484, Dec. 1977.

TENDULKAR, Rohini; HANCOCK, Gigi. Corporate bond markets: a global perspective. Staff Working of the International Organization of Securities Commissions (IOSCO) Research Department, v. 1, p. 3, Apr. 2014. Disponível em: https://www.iosco.org/research/pdf/swp/ SW4-Corporate-Bond-Markets-Vol-1-A-global-perspective.pdf. Acesso em: 27 jun. 2018.

TORRES FILHO, Ernani Teixeira. O BNDES em uma encruzilhada: como evitar sua desmontagem. São Paulo: Instituto de Estudos para o Desenvolvimento Industrial - IEDI, 2018 . 
TORRES FILHO, Ernani Teixeira. O crédito corporativo de longo prazo em uma encruzilhada: onde estamos e para onde podemos ir?. São Paulo: Instituto de Estudos para o Desenvolvimento Industrial - IEDI, 2017.

TORRES FILHO, Ernani Teixeira; COSTA, Fernando Nogueira da. Financiamento de longo prazo no Brasil: um mercado em transformação. Texto para Discussão, Rio de Janeiro, n. 1843, 2013.

TREVISAN, Marco Antonio. O oportunismo contratual e os mecanismos jurídicos de governança sob a perspectiva de law \& economics e de suas novas questões teóricas. 2015. 361 f. Tese (Doutorado em Direito) - Universidade de São Paulo, São Paulo, 2015.

ZONENSCHAIN, Claudia Nessi. Estrutura de capital das empresas no Brasil. Revista do Banco Nacional do Desenvolvimento (BNDES), dez. 1998. Disponível em: https://www. bndes.gov.br/SiteBNDES/export/sites/default/bndes_pt/Galerias/Arquivos/conhecimento/ revista/rev1003.pdf. Acesso em: 1. ${ }^{\circ}$ jul. 2018. 